\title{
Alzheimer's disease: amyloid-based pathogenesis and potential therapies
}

\author{
Yixiu Zhou ${ }^{1}$, Yuhui Sun ${ }^{2}$, Quan-Hong Ma ${ }^{2}$ and Yaobo Liü,** \\ ${ }^{1}$ Medical College of Soochow University, Soochow University, Suzhou, Jiangsu 215004, China. \\ ${ }^{2}$ Jiangsu Key Laboratory of Neuropsychiatric Diseases and Institute of Neuroscience, Soochow University, Suzhou, Jiangsu 215123, \\ China. \\ * Corresponding Author: \\ Yaobo Liu, Institute of Neuroscience, Soochow University, 199 Ren-Ai Road, Suzhou, Jiangsu 215123, China; Phone/Fax: 86-512- \\ 65882526; E-mail: liuyaobo@suda.edu.cn
}

\begin{abstract}
Alzheimer's disease is one of the most severe neurodegenerative diseases among elderly people. Different pathogenic factors for Alzheimer's disease have been posited and studied in recent decades, but no effective treatment has been found, necessitating further studies. In this Viewpoint article, we assess studies on the mechanisms underlying the accumulation of amyloid $\beta(A \beta)$ peptide and the formation of $A \beta$ oligomers because their accumulation in amyloid plaques in brain tissue has become a well-studied hallmark of Alzheimer's disease. We focus on the production of $A \beta$ and its impact on the function of synapses and neural circuits, and also discuss the clinical prospects for amyloid-targeted therapies.
\end{abstract}

doi: $10.15698 /$ cst2018.07.143

Received originally: 14.02 .2018

in revised form: 20.05.2018,

Accepted 24.06.2018.

Published 29.06.2018.

Keywords: Alzheimer's disease $(A D)$, amyloid $B(A B)$, synapses, neural circuits, treatment.
Abbreviations:
$A \beta$ - amyloid $\beta$,
$A D$ - Alzheimer's disease,
$A P P$ - amyloid precursor protein
$B B B$ - blood-brain barrier,
$F A D$ - familial $A D$,
$L D L R$ - low-density lipoprotein
receptor,
LTD - long-term depression,
LTP - long-term potentiation,
NMDA - N-methyl-D-aspartic
acid
NMDAR - NMDA receptor,
$\operatorname{PrP}^{C}$ - cellular prion protein.

\section{INTRODUCTION}

Alzheimer's disease (AD) is one of the most prevalent forms of dementia; in 2015, for example, AD affected $\sim 46.8$ million people worldwide. It is estimated that this number will continue to increase and reach 131.5 million in 2050 [1]. In China in 2014, for instance, $\sim 10 \%$ of the population was 60 years of age or older ( 212 million people), according to the National Bureau of Statistics of China [2]. Recent increase in life expectancy may greatly expand the future $A D$ burden [3], and indeed, $A D$ will have a larger impact on the economy of China and of the world [3]. Thus, a great deal of effort has been spent on studying the pathological mechanism of $A D$ and on trying to find a treatment to cure $A D$. In this Viewpoint, we discuss one of the most central hypotheses, namely the amyloid cascade hypothesis, and subsequent research that complements or challenges it. A fundamental aspect of research on $A D$ concerns the involvement of amyloid $\beta(A \beta)$ in the pathophysiology of the disease and as a possible target for treatment. Despite these efforts, however, no anti-amyloid therapy has yet been established [4]. Hence, this Viewpoint focuses on attempts to research on amyloid-based pathogenesis and develop an amyloid-targeted therapy.

THE AMYLOID CASCADE HYPOTHESIS AND SUBSEQUENT STUDIES

One of the characteristic pathologies of $A D$ is the presence of parenchymal amyloid plaques in the brain tissue of pa- 
tients [5]. $A \beta$ was first isolated from the meningeal vessels of AD patients in 1984 [6]. One year later, the same peptide was identified as the core of senile plaques observed in the brain tissue of AD patients [7]. These findings called researchers' attention to the accumulation of the amyloid protein. Moreover, it was discovered that Down syndrome (trisomy 21) patients often develop AD later in life and the amyloid precursor protein (APP) gene is located on chromosome 21 [8]. Thus, the amyloid cascade hypothesis was first posited in 1992, which postulates that the accumulation of $A \beta$ peptides initiates the pathogenesis of $A D$, leading to neurofibrillary tangles and neurodegeneration that cause memory loss [9]. Hardy et al. proposed that the overproduction of $A \beta$ results from hyperactivation of the $\beta$ and $\gamma$ secretases (gain-of-function mechanism), which cleave APP and yield A [8]. In the years since the hypothesis was proposed, the $A \beta$ peptide has been a star molecule in most of the research on the pathophysiology of $A D$.

The amyloid cascade hypothesis has generated a lively discussion whether plaques are neurotoxic or protective. Although it was previously believed that plaques are the initiators of disease pathogenesis, Lee et al. argued that all available data are also consistent with the conclusion that amyloid plaques actually constitute a protective adaptation [10]. Meanwhile, Bishop et al. found that this apparent paradox became evident when $A \beta$ was bound to metal ions, and the resulting complex could be neurotoxic or neuroprotective [11]. Moreover, it has been reported that soluble $A \beta$ oligomers can impair synapse structure and function and that the smallest synaptotoxic species are dimers, whereas neither $A \beta$ monomers nor soluble amyloid plaque cores significantly alter synaptic plasticity [12]. Now it is generally agreed that the soluble $A \beta$ oligomers, rather than amyloid plaques, are synaptotoxic.

Aside from the debate concerning amyloid plaques and oligomers, new findings have arisen supporting the amyloid cascade hypothesis. Jonsson et al. made an astonishing discovery that a coding mutation (A673T) in the APP gene could protect against $A D$ and cognitive decline in an elderly population with $A D$, which indicated that a reduction of $\beta$ cleavage of APP might protect against AD [13]. He et al. found that $A \beta$ enhanced tau pathogenesis by creating a unique environment that facilitated tau aggregation at an early stage and helped translocate the tau "seeds" at a later stage [14].

However, although the accumulation of $A \beta$ is acknowledged as a key factor in the cognitive deficit observed in $A D$ patients, other studies have pointed out the weakness of the original amyloid cascade hypothesis and pointed out some challenges. Researchers raised concerns about the amyloid cascade hypothesis based on studies of familial $A D$ (FAD), which is attributable to mutations in one of three genes, namely presenilin1 (PSEN1), presenilin2 (PSEN2), or APP [15]. Among them, presenilin1 and presenilin2 are the core components of $\gamma$-secretase, which cleaves the Cterminal fragment of APP produced by $\beta$-secretase cleavage within the plasma membrane, releasing $A \beta$ [16]. Thus, many studies on FAD have focused on mutations in the gene encoding $\gamma$-secretase. For instance, Xia et al. suggested that PSEN1 gene mutations could both abolish $\gamma$ secretase activity, which decreases the production of $A \beta 42$ and $A \beta 40$, and increase the $A \beta 42 / A \beta 40$ ratio, which promotes $A \beta$ deposition through a loss-of-function mechanism linked to familial AD onset [17]. Ben-Gedalya et al. reported that inhibition of cyclophilin B leads to presenilin1 misfolding, aggregation, and deposition, which reduces $\gamma$ secretase function and thus opposes the gain-of-function mechanism [18]. However, Szaruga et al. expressed doubt about the loss-of-function hypothesis and proposed an alternative view that "pathogenic mutations in PSEN cause disease by qualitative shifts in $A \beta$ profile production ( $\gamma$ secretase dysfunction)" [19]. In response to these challeng es, Hardy et al. later argued that the loss-of-function hypothesis might overlook the elevation of $A \beta 43$ and of other, longer A $\beta$ species [20].

Moreover, some researchers have suggested that the simple linear pathway of tracing disease progression from $A \beta$ to $A D$ should be rejected [21]. Some clinical studies have reported that cognitive decline correlates only weakly with changes in $A \beta$ burden and that a window of time exists between $A \beta$ accumulation and $A D$ onset [22]. Moreover, although the antineoplastic drug bexarotene rapidly clears amyloid plaques in mouse brain and reverses the cognitive decline of the mice [23], clinical trials with humans have not proved promising. For instance, the drug AN1792 could eliminate amyloid plaques quite well, but it could not reverse the neurodegeneration [24]. Thus, the opinion that the amyloid cascade hypothesis should be rejected is based on the fact that $A \beta$ accumulation does not correlate with the immediate onset of $A D$ and that elimination of amyloid plaques cannot stop neurodegeneration. However, because $A \beta$ plaques are not necessarily sources of toxicity, as mentioned above, more evidence may be needed before the amyloid cascade hypothesis can be soundly rejected.

Also, compared with early-onset FAD, lateonset/sporadic $A D$, which affects most $A D$ patients, has shown a different mechanism for pathogenesis. Indeed, most sporadic AD cases display normal $\gamma$-secretase activity, in contrast to FAD [19]. Moreover, neurofibrillary tangles develop sooner in PSEN-FAD, portending more rapid neuronal demise [25]. However, Thomas et al. suggested that changes in functional connectivity manifest similarly in both types of $A D$, and therefore early-onset $A D$ might serve as a model for late-onset AD studies [26].

Thus, there are different and competing views regarding the amyloid cascade hypothesis, and no definite conclusions can be drawn at this time.

\section{PRODUCTION OF A}

The $A \beta$ peptides are proteolytic fragments derived from APP, which is an integral membrane protein found to exhibit both neurotoxic and neurotrophic protective effects [16]. The human APP gene is located on the long arm of the chromosome 21, and alternative splicing can produce various APP mRNAs encoding several isoforms [27]. The 
most common APP species in the brain is APP695, and it is produced mainly by neurons [28]. APP is synthesized and transported to the plasma membrane via the endoplasmic reticulum-Golgi secretory pathway [29]. Also, it has been proposed that APP can function as a cell-surface receptor, which can be bound by $A \beta$ and regulate the production and downstream signaling of $A \beta$ [27]. APP is transported along axons to presynaptic terminals, where it accumulates and leads to $A \beta$ deposition at synapses [28]. Notably, two pathways are known to process APP, namely the amyloidogenic and non-amyloidogenic pathways [16], and the latter is the principal pathway under physiological conditions [30].

In the non-amyloidogenic pathway (Fig. 1A and Fig. 1B), APP is first cleaved by $\alpha$-secretase, which is a member of the ADAM (A Disintegrin And Metalloproteinase) family and is abundant at the plasma membrane. This cleavage yields the soluble ectodomain SAPP $\alpha$ and leaves the Cterminal fragment alpha (CTF $\alpha$ ) in the plasma membrane. Subsequent cleavage of CTF $\alpha$ by $\gamma$-secretase releases a soluble extracellular peptide (p3) and the APP intracellular domain (AICD) [16]. Of note, the APP holoprotein can be bound by various low-density lipoprotein receptors (LDLRs), such as SORL1, which is an APP-specific sorting receptor. Any APP that binds LDLRs can be internalized and enters a recycling pathway. The absence of LDLRs can shunt APP into the $\beta$-secretase cleavage pathway (the amyloidogenic pathway) [31].

The amyloidogenic pathway (Fig. 1A and Fig. 1B) involves APP trafficking through the secretory and recycling pathways where APP interacts with $\beta$ - and $\gamma$-secretases [32]. After APP is internalized and delivered to endosomes [30], the first step of the pathway is catalyzed by $\beta$ secretase 1 (BACE-1), a single-transmembrane aspartyl protease. BACE-1 cleaves APP and generates the soluble ectodomain SAPP $\beta$ and CTF $\beta$ (left in the membrane). The subsequent hydrolysis of CTF $\beta$ by $\gamma$-secretase yields AICDs and $A \beta$ monomers, which have dual physiological effects [16]. The majority of $A \beta$ peptides are secreted to the extracellular space, although a small amount can aggregate inside neurons [30], whereas AICD is transported into the nucleus where it functions as a transcription factor [29]. In addition, $\gamma$-secretase cleaves CTF $\beta$ at different sites and in multiple sequential steps, which ultimately produces mainly two species of $A \beta$, namely $A \beta 40$ and $A \beta 42$ [27]. Under basal conditions, $A \beta 40$ comprises $\sim 90 \%$ of all $A \beta$ produced [16].

The fact that various $A \beta$ species are produced has a pathogenic impact on neurons, and the longer $A \beta 42$ is believed to be more toxic than $A \beta 40$ [33]. In addition, it has been reported that the ratio of $A \beta 42$ to $A \beta 40$ might predict the severity of $A D$ [34], and indeed, this ratio has long been used as a biomarker in AD research. Early studies reported that PSEN mutations increase the $A \beta 42 / A \beta 40$ ratio [17]. In the amyloidogenic pathway, $\gamma$-secretase can trim the epsilon site and gamma site of the transmembrane CTF $\beta$. Thus, both mutations in the domain of the epsilon/gamma sites and the $\gamma$-secretase modulators can influence $A \beta 42$ pro- duction. Mutations in the transmembrane domain of APP can increase the $A \beta 42 / A \beta 40$ ratio, leading to aggressive early-onset FAD, whereas $\gamma$-secretase modulators can decrease the level of $A \beta 42$ and thus have therapeutic potential [35]. In a recent investigation, Johnson et al. proposed that, under physiological conditions, small $A \beta$ oligomers bound to the plasma membrane and further oligomerized with kinetics depending on the local $A \beta 42 / A \beta 40$ ratio [36]. Siegel et al. discovered that the ratio was greatest for $A \beta^{\prime}$ (the $\mathrm{N}$-terminally truncated $A \beta_{11-x}$ produced from the 89 residue $C T F$ ), followed by $A \beta$ and then $p 3$, which provided new insight for the development of $\gamma$-secretase modulators [37]. Moreover, others suggested that the ratio could be used as the biomarker for the diagnosis of neurochemical dementia $[38,39]$ as well as in clinical trials targeting cognitively normal individuals with high brain $A \beta$ levels [40].

Once the $A \beta$ monomer is produced, it either goes through the degradation process or accumulates to form other species of amyloids, such as oligomers, fibrils, etc. There are two main mechanisms by which amyloids are removed from cells. First, the monomer that forms in endosomes can be transferred to lysosomes in the neuron, where it is degraded. Second, if the monomer is released to the outside of the neuron, microglia can destroy it by releasing insulin-degrading enzyme [29]. Aside from this, there are two models for the formation of $A \beta$ fibrillogenesis. The classic model posits that fibril formation is a nucleation-dependent polymerization process in which monomers give rise to oligomers, from which protofibrils form. Subsequently the protofibrils emanate full-length fibers. The new model, however, implies that protofibrils cannot form fibrils directly. Instead, protofibrils may be the precursors for fibrillogenesis [41]. Also, after studying several species of amyloids, i.e., monomers, oligomers, $A \beta^{*} 56$, etc., Ono noted that "soluble pre-fibrillar aggregates, that is, oligomers of $A \beta$, are proximate neurotoxins" [41].

Compared with $A \beta 42$, which has been studied for many years, $A \beta 43$ has been quite overlooked. A study published in 2011 , however, suggested that $A \beta 43$ is potentially toxic and amyloidogenic, perhaps to an extent greater than A $\beta 42$ [42].

A new APP processing pathway was recently identified. This pathway generates proteolytic fragments of APP capable of inhibiting neuronal activity within the hippocampus. The cleavage of APP by $\eta$-secretase yields CTF $\eta$, which is cleaved by ADAM10 and BACE1 into long and short amyloid eta $(A \eta \alpha, A \eta \beta)$. CTF $\eta$ is abundant in dystrophic neurites, and its generation is usually mediated by membranebound matrix metalloproteinase [43]. Also, A 342 disrupts the barrier between the blood and cerebrospinal fluid via activation of matrix metalloproteinase [44]. Thus, a connection may exist between these two pathways.

\section{A $\beta$ AFFECTS SYNAPTIC AND NEURAL CIRCUIT FUNC- TION}

As mentioned above, $A \beta$ peptide plays an important role in $A D$ by influencing synapses and, in turn, neural circuits. 

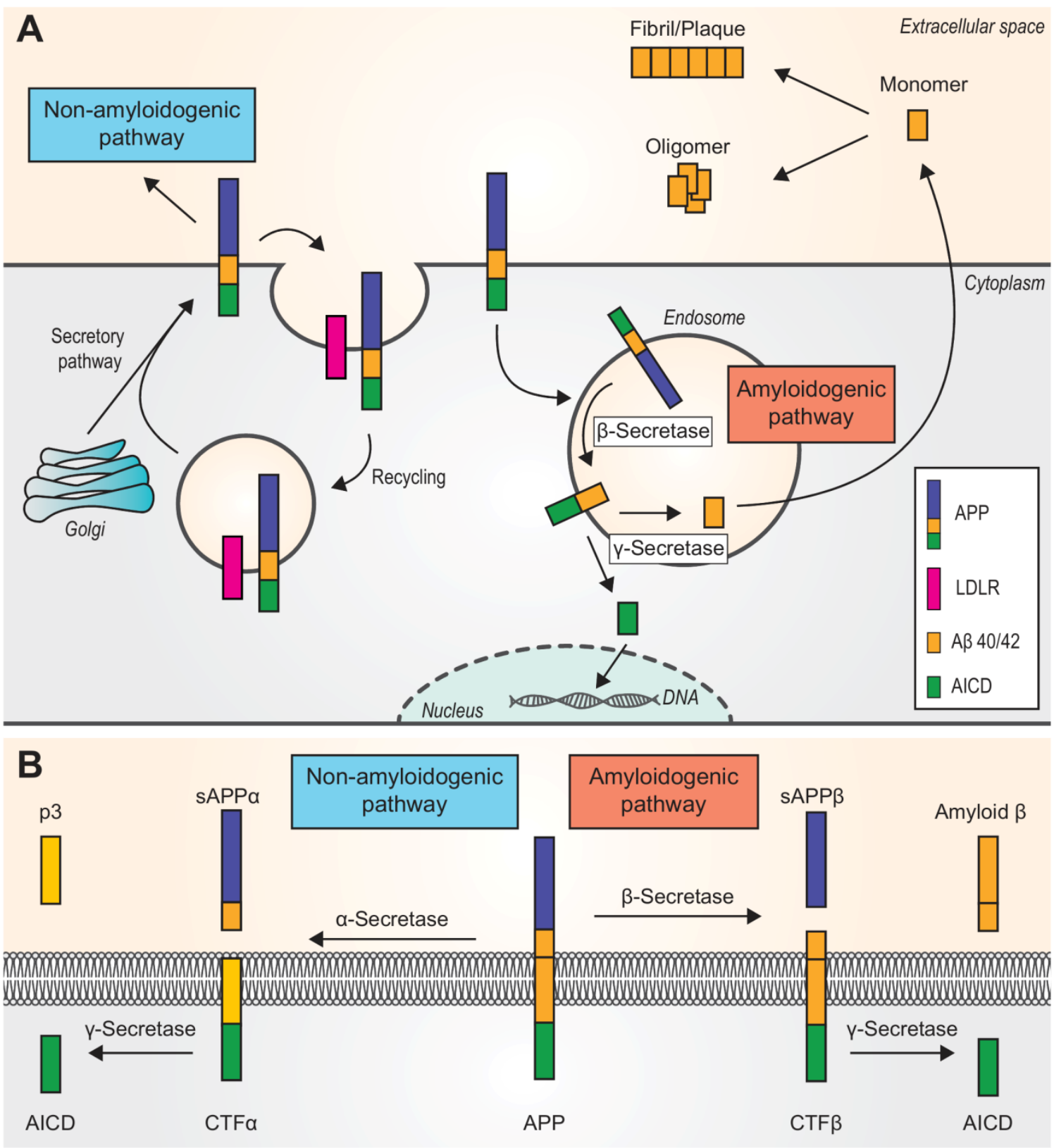

FIGURE 1: Two pathways of amyloid $\boldsymbol{\beta}(\mathbf{A} \boldsymbol{\beta})$ peptides generation. Amyloid precursor protein (APP) is a type I integral membrane protein that is cleaved at different sites to yield various products. (A) An overview of the two pathways. APP is translocated from the cytoplasm into the endoplasmic reticulum where it enters the secretory pathway and then is transported to the neuronal plasma membrane. The majority of APP is processed via the non-amyloidogenic pathway (see panel B). APP can be recycled in endosomes by binding to LDLRs (low-density lipoprotein receptors). The right side of the figure shows the amyloidogenic pathway. Unlike the non-amyloidogenic pathway, which is carried out at the plasma membrane, the amyloidogenic pathway mainly occurs in endosomes. Ultimately, AICD is transferred to the nucleus, where it functions as a transcriptional factor, whereas the A $\beta 40 / 42$ monomer is removed to the extracellular space. Monomers aggregate either into oligomers or fibrils/plaques. (B) Non-amyloidogenic (left) or amyloidogenic (right) pathway of APP processing. In the nonamyloidogenic pathway, APP is first cleaved by $\alpha$-secretase, releasing a soluble ectodomain of APP called sAPP $\alpha$ and a membrane-tethered intracellular C-terminal fragment (CTF $\alpha$ ). Then, the C-terminal fragment is further cleaved by $\gamma$-secretase to produce a 3-kDa peptide ( $\mathrm{p} 3$ ) and an APP intracellular domain (AICD). In the amyloidogenic pathway, the products of $\beta$-secretase are a soluble ectodomain of APP (sAPP $\beta$ ) and a C-terminal fragment $\beta$ (CTF $\beta$ ). The second step releases Amyloid $\beta$ and AICD. APP, amyloid precursor protein. CTF alpha/beta, Cterminal fragment alpha/beta. SAPP alpha/beta, soluble ectodomain of APP. p3, 3-kD peptide. AICD, APP intracellular domain.

Accumulation of $A \beta$ in the brain parenchyma can lead to loss of dendritic spines and synapses as well as alterations in synaptic transmission and neural activity [45].
Although overproduction of the $A \beta$ oligomer is pathogenic, a normal level of $A \beta$ helps to maintain physiological homeostasis. A study using mouse/rat hippocampal slices 
suggested that $A \beta$ might have a normal negative feedback function that regulates APP processing; in that study, Kamenetz et al. proposed that an elevated level of neuronal activity could enhance the activity of $\beta$-secretase, which would generate $A \beta$ monomers. Overproduction of these monomers leads to synaptic depression, which in turn suppresses neuronal activity and further reduces $A \beta$ production [46]. This constitutes a protective mechanism that modulates the production of $A \beta$ monomers and can prevent monomer overproduction in nearby neurons. Nevertheless, a study using APP-transfected neurons in rat hippocampal slice cultures revealed that structural plasticity was reversibly impaired in APP-overexpressing cells [47]. Continuous overproduction of $A \beta$ oligomers at either dendrites or axons can lower spine density and plasticity; this "synaptic pruning" in spine number can be reduced by blocking action potentials, nicotinic acetylcholine receptors (nAChRs), or N-methyl-D-aspartic acid (NMDA) receptors (NMDARs) [47]. A $\beta$-mediated spine loss requires the upregulation of NMDA-type glutamate receptor-dependent activity and the subsequent cascade of signaling that includes cofilin and calcineurin. Shankar et al. experimented on mouse hippocampal neurons and found that activation of NMDARs could induce either long-term depression (LTD) or long-term potentiation (LTP) depending on the $\mathrm{Ca}^{2+}$ concentration. Soluble $A \beta$ oligomers can partially block NMDARs, which either reduces $\mathrm{Ca}^{2+}$ influx or enhances NMDAR-dependent activation of calcineurin. Decreased $\mathrm{Ca}^{2+}$ influx through NMDARs can induce LTD through a calcineurin-dependent pathway [48]. Also, GSK3 activity stimulated by $A \beta$ may lead to NMDAR-dependent LTD and inhibit LTP [49], resulting in loss of synaptic spine and eventually neurodegeneration [50].

Because the dendritic spine is part of a synapse, spine loss can also affect synaptic activity. It has been suggested that $A \beta$ oligomers play a central role in controlling neural activity at specific types of synapses which affects the neural circuits [51]. Aside from NMDARs, $A \beta$ oligomers are heterogeneous and have high affinity to specific types of receptors, which activate various signaling pathways leading to inevitable cell death [52]. For instance, Lauren et al. identified the cellular prion protein $\left(\operatorname{PrP}^{C}\right)$ as an $A \beta$ oligomer receptor by expression cloning and discovered that $\mathrm{PrP}^{C}$ mediated the inhibition of LTP in a wild-type mouse hippocampal slice by the binding of $A \beta 42$ oligomers. Presumably, $\operatorname{PrP}^{C}$ interacts with NMDAR subunit $2 \mathrm{D}$ and inhibits its function by initiating a signaling cascade that modifies synaptic morphology and functions in the brain [53]. Kim et al. observed that murine PirB (paired immunoglobulin-like receptor $B$ ) was associated with memory deficits in adult mice as well as loss of synaptic plasticity in the juvenile visual cortex. The selective binding of $A \beta 42$ to PirB could lead to increased interactions between PirB and cofilin or protein phosphatases in APP/presenilin1 mice. They proposed that the human homolog LilrB2 (leukocyte immunoglobulin-like receptor B2) might also enhance cofilin signaling, which is seen in the human $A D$ brain [54]. Yamamoto et al. suggested that $A \beta$ oligomers can lead to nerve growth factor receptor-mediated cell death through the p75 neurotrophin receptor [55]. Zhao et al. reported that $A \beta$ oligomers can impair the function of neuronal insulin receptors in rat hippocampal and cortical neurons, indicating that insulin resistance in the $A D$ brain is a response to the $A \beta$-derived diffusible ligands (ADDLs) [56]. Moreover, insulin receptor-mediated interference with $A \beta$ production prevented the rapid activation of a specific kinase required for LTP [57]. Also, Magdesian et al. found that A $\beta$ oligomers could bind to the Frizzled cysteine-rich domain at, or in close proximity to, the Wnt-binding site and inhibit the canonical Wnt signaling pathway, which caused tau phosphorylation and neurofibrillary tangles [58]. Moreover, it has even been reported that $A \beta$ peptides can form oligomeric ion channels, assisted by cholesterol, and that these channels can induce an increase of $\mathrm{Ca}^{2+}$ level in neurons [59]. Furthermore, coupled with the increase in membrane permeability induced by $A \beta$ oligomers [60], the channels can disrupt $\mathrm{Ca}^{2+}$ homeostasis and lead to neurodegeneration.

Normally, a small increase in $A \beta$ level will increase the probability of releasing synaptic vesicles (Fig. 2A). Such an increase can promote activation of presynaptic acetylcholine receptors, which increases the internal concentration of $\mathrm{Ca}^{2+}$. The high concentration of $\mathrm{Ca}^{2+}$ increases glutamate release and promotes excitatory neural activity $[51,61]$. $A \beta$ can participate in a positive feedback loop in which it binds to $n A C h R s$ that are close to the site of $A \beta$ secretion, resulting in increased intracellular $\mathrm{Ca}^{2+}$. An increase in $\mathrm{Ca}^{2+}$ concentration may increase $A \beta$ production [47]. It is possible that an excessive increase of $A \beta$ will lead to the aforementioned negative feedback loop and eventually to compensatory suppression of the neuronal activity [46]. Palop et al. suggested that $A \beta$ can trigger intermittent and aberrant excitatory neuronal activity in the cortex and hippocampus, which might result in remodeling of the inhibitory circuitry. They proposed that a "high level of $A \beta$ induces aberrant excitatory neuronal activity, which triggers compensatory inhibitory mechanisms to counteract overexcitation", and both the excitation and inhibition might be involved in $A D$ related network dysfunction [62]. A high level of $A \beta$ leads to aberrant neuronal activity by enhancing synchrony among the remaining glutamatergic synapses [51]. The acute effects induced by endogenous $A \beta$ in certain studies were exclusively presynaptic. An increase or significant decrease in $A \beta$ level impairs short-term synaptic facilitation [61]. Thus, the level of $A \beta$ must be maintained within an intermediate range, and either a low or high level can negatively impact presynaptic facilitation by decreasing presynaptic efficacy or postsynaptic depression. It has been suggested that excitatory synapses are highly sensitive to changes in $A \beta$ level, whereas inhibitory synapses are relatively immune to the immediate effects of $A \beta$ [61]. The relative decrease in inhibition can lead to hyperactivity as well as abnormal synchronization [63]. In addition, Siskova et al. reported that interneurons can alter their excitability and synchronizing function owing to cell type-specific vulnerability and/or persistently altered input. Thus, dendritic 


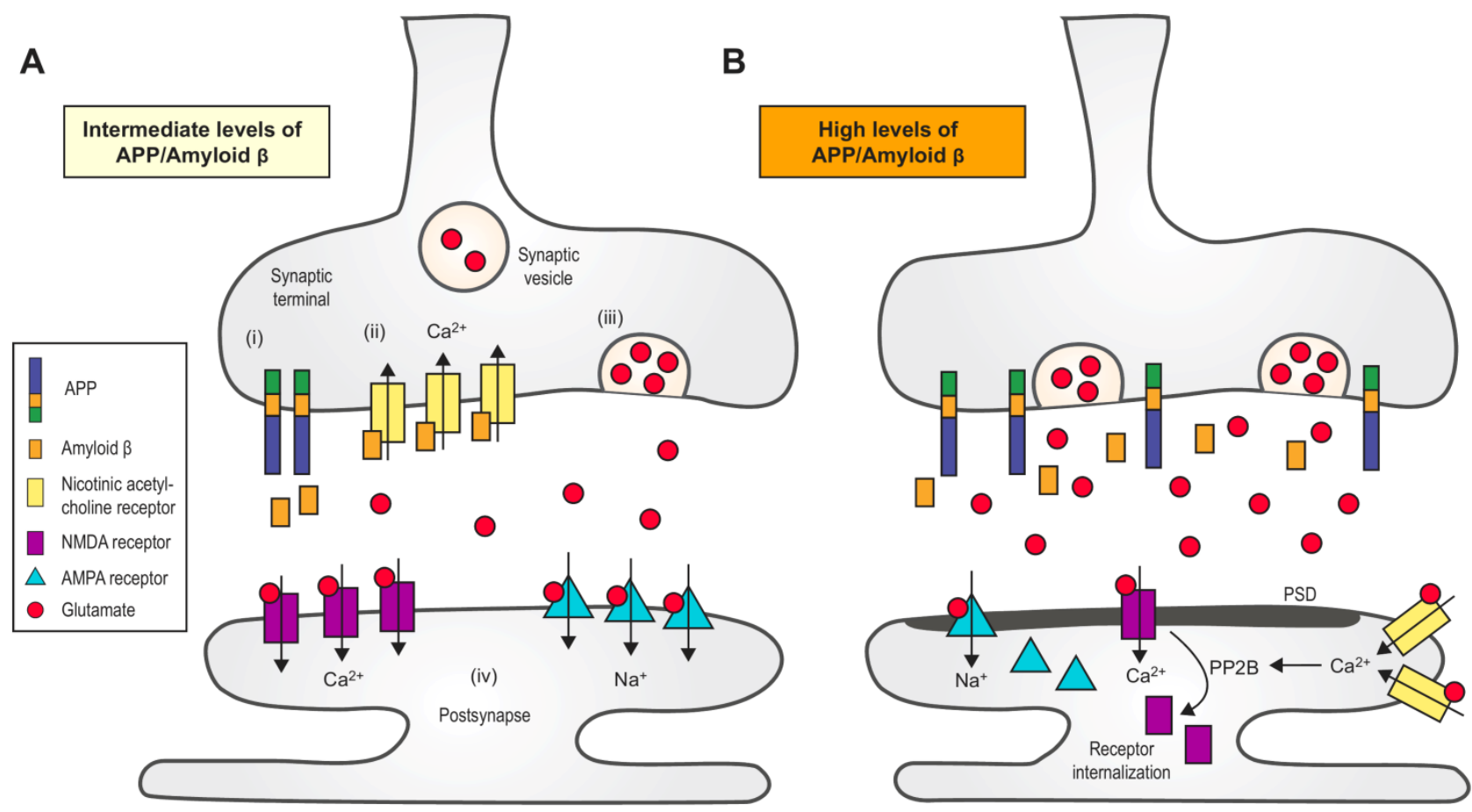

FIGURE 2: Synaptic transmission regulated by amyloid $\beta$ (AB). (A) An intermediate increase in $A \beta$ level can only increase the probability of releasing synaptic vesicles. The processing of amyloid precursor protein (APP) at the synaptic terminal yields $A \beta$ peptides (i), which bind to and activate the presynaptic $\alpha 7$-nAChRs (ii). Moreover, the subsequent influx of $\mathrm{Ca}^{2+}$ is mediated by nAChRs, which, in turn, trigger the release of glutamate from the synaptic vesicles (iii). Glutamate activates both AMPARs and NMDARs, which induce synaptic potentiation (iv). (B) A dramatic increase of $A \beta$, however, can lead to LTD. First, accumulation of glutamate results in the long-term activation of NMDARs and AMPARs, which facilitates their internalization. Second, $A \beta$ might redistribute NMDARs. Third, the activation of perisynaptic $\alpha 7$-nAChRs activates the protein phosphatase $2 \mathrm{~B}$ (PP2B), a $\mathrm{Ca}^{2+}$-sensitive enzyme that induces the internalization of NMDARs [67]. $\alpha 7-n A C h R, \alpha 7$-nicotinic acetylcholine receptor. PSD, post-synaptic density. NMDAR, N-methyl-D-aspartate receptor. AMPAR, $\alpha$ amino-3-hydroxy-5-methyl-4-isoxazolepropionic acid receptor.

structural dysfunctions may be linked to neuronal hyperexcitability [64].

A small increase in $A \beta$ will enhance LTP and memory [61], whereas an acute increase in synaptic $A \beta$ can induce LTD instead $[51,65]$. A decrease in the density of postsynaptic glutamate receptors, such as AMPARs and NMDARs, and the activation of the calcineurin-dependent pathway, which is involved in $A \beta$-induced spine loss, is also necessary for LTD [49]. Accumulation of glutamate initially results in postsynaptic depolarization through AMPARs and then the activation of NMDARs [66]. However, long-term activation leads to receptor desensitization and internalization of NMDARs and AMPARs. Moreover, the binding and activation of $A \beta$ on alpha-7 nAChRs induces endocytosis of NMDARs through the action of protein phosphatase $2 B$ [67]. Changes in the number of the NMDARs can affect NMDAR-dependent $\mathrm{Ca}^{2+}$ influx, which is responsible for initiating LTD (Fig. 2B). Activation of perisynaptic NMDARs can lead to LTD [66], and over-activation of extrasynaptic NR2B-containing NMDARs can inhibit hippocampal LTP. Soluble $A \beta$ increases the phosphorylation of p38 MAPK, which contributes to the inhibition of LTP and subsequently impairs the ERK and CREB signaling pathway [68]. Um et al. demonstrated that $A \beta o / \operatorname{PrP}^{C}$ complexes could activate the Fyn signaling pathway, which increases the density of cell-surface NMDARs and excitotoxicity, resulting in the loss of both dendritic spines and cell-surface receptors [69].

It has been suggested that the formation of neural circuits and memories is impaired by weakened connectivity owing to chronic elevation of $A \beta$ [47]. An increased level of $A \beta$ results in an aberrant excitatory network and compensatory inhibition of learning and memory circuits, which promotes cognitive decline [62]. Long-term accumulation of $A \beta$, disinhibition of excitatory cells, and synaptic loss lead to neuronal hyperactivity, which may lead to epileptiform activity $[45,70]$. Coincidently, in some presymptomatic individuals who eventually develop $A D$, neuronal hyperactivity was found in regions - such as hippocampus - that are associated with learning and memory [45]. Additionally, AD impairs slow wave oscillations, which consolidate recently acquired memories in the cortical area, thalamus, and hippocampus [63]. Moreover, excessive oligomeric $A \beta$ binding to cell-surface receptors can induce neuronal apoptosis [52]. Long-term accumulation of $A \beta$ results in oxidative damage to both DNA and proteins, 
which also leads to cell death [71] and impairs the affected brain regions, although the level of $A \beta$ plateaus before the onset of rapid neurodegeneration and cognitive symptoms [72]. Thus, excessive neuronal activity, hyper-synchrony, impaired oscillations, and cell death, etc., could be key features of $A D$. It should be noted that aside from $A \beta, G A$ BAergic dysfunction also contributes to the formation of the aberrant neural networks that are typical of $A D$ [51]. Thus, diverse mechanisms may contribute to neural network dysfunction in AD.

\section{TREATMENT BASED ON A $\beta$ HAS NOT BEEN ENTIRELY SUCCESSFUL}

Owing to its key role in $A D$, amyloid-targeted therapy has become a major research interest. There are two main ways to reduce excessive level of $A \beta$ in neurons, namely (i) to correct the aberrant generation of $A \beta$ and (ii) repair the faulty clearance mechanism (Fig. 3).

One attractive therapeutic strategy to reduce $A \beta$ production are drugs that modulate the activity of the enzymes $\beta$-secretase or $\gamma$-secretase, especially inhibitors of $\beta$ secretase (BACE-1). Although considerable efforts have been made to develop BACE-1 inhibitors, most trials have failed due to insufficient target specificity, brain permeability, and/or research design without testing cognitive outcomes or measuring $A \beta$ level $[71,73]$. The first generation of large-molecule drugs failed because of their unfavorable pharmacological properties, such as the inability to cross the blood-brain barrier (BBB), and the second generation of small-molecule compounds still could not effectively penetrate the BBB [71]. The third-generation drugs, such as verubecestat (Merck \& Co.), AZD-3293 (AstraZeneca and Eli Lilly), and JNJ-54861911 (Janssen Research \& Development), are BACE-1 inhibitors currently in Phase III trials [74]. In February 2017, Merck halted its late-stage trial of verubecestat for mild-to-moderate Alzheimer's disease (EPOCH) after it was reported as having "virtually no chance of finding a positive clinical effect" according to an independent panel of experts [75]. With respect to patients with prodromal Alzheimer's disease (APECS), however, the results of Merck's trial of verubecestat for that purpose are expected in February 2019 [75]. However, AZD3293 yielded favorable results in Phase I; this compound can cross the BBB and is orally active and well tolerated up to the highest dose given. In September 2014, a large, pivotal phase II/III trial (AMARANTH) started and another Phase III trial (DAYBREAK-ALZ) was initiated in 2016 for AD patients with mild dementia. These trials will end in 2019 and 2021, respectively [76]. As for $\gamma$-secretase, the failure to develop an inhibitor is attributable to a limited understanding of the structure of $\gamma$-secretase. Inhibitors like semagacestat proved ineffective in clinical trials [73]. Although previous results were not satisfying, peptide-based aggregation inhibitors hold significant promise for future $A D$ therapy owing to their high selectivity and low toxicity, among other attributes [77].

Alternatively, both active and passive strategies of immunization with the peptide are potential routes to en-

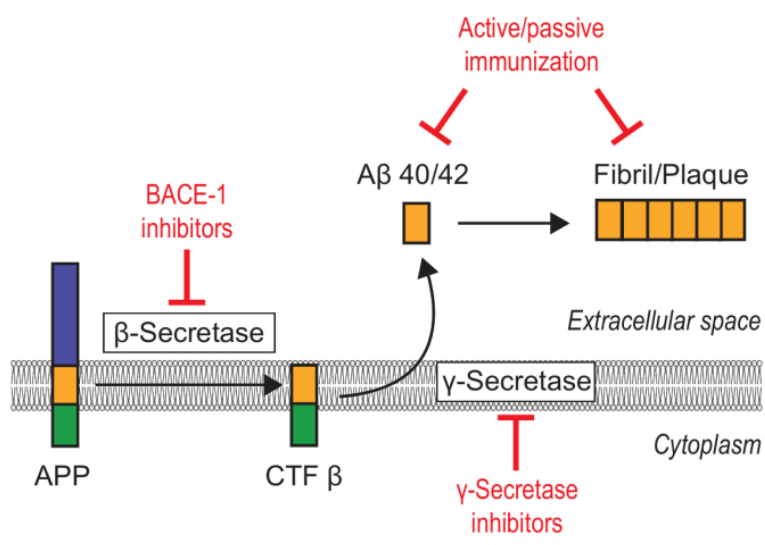

FIGURE 3: Current treatment strategies based on the amyloid cascade hypothesis. Recent or ongoing clinical trials have mainly focused on inhibition of $\beta$-secretase (BACE-1), $\gamma$-secretase, or immunization strategies against $A \beta$ monomers or plaques. See text for details. CTFB, C-terminal fragment beta.

hance amyloid plaque clearance in the parenchyma. Active immunization is achieved via immunization with intact $A \beta 42$ peptide or $A \beta$ fragments, whereas passive immunization is achieved with anti-A $\beta$ antibodies [78].

Some of the trials that have focused on active immunization with $A \beta$ succeeded in reducing the level of $A \beta$ peptide in patients, but with severe side effects, such as subacute meningoencephalitis (AN1792, Janssen, Pfizer) [79]. Although the trials were halted, subsequent investigations were carried with former participants. Holmes et al. reported that AN1792 could eliminate amyloid plaques fairly well, but the treatment did not stop the process of neurodegeneration [24], which lends credence to the opinion that amyloid plaques are not necessarily neurotoxic. Another study in 2015 showed that AN1792 could accelerate the removal of damaged neurons involving activated microglia [80]. Aside from AN1792, investigators have also developed other active immunization strategies. For instance, Mulder et al. demonstrated that a trivalent vaccine of small $A \beta$-derived cyclopeptide conjugates could effectively induce a specific antibody response against misfolded $A \beta$ without noticeable side effects [81]. Further, a trial with CAD106 (Novartis Pharmaceuticals Corporation) is now in Phase II/III after five multicenter Phase II trials. Unlike AN1792, CAD106 is generally well tolerated, with no evidence of central nervous system inflammation [82] Recently, a P-particle-based $A \beta$ epitope vaccine showed promise by reducing amyloid deposition, rescuing memory loss, and restoring $A \beta$ homeostasis in vivo [83]. Thus, active immunization might still be a potential therapy for AD.

In recent years, research interests have focused on developing monoclonal antibodies against $A \beta$; for example, solanezumab against the middle region of $A \beta$ (developed by Ely Lilly), aducanumab against aggregated $A \beta$ (tested by Biogen), and bapineuzumab against the $N$-terminus of $A \beta$ (directed by OOP \& Johnson), among others. The efficacy of $A \beta$ immunization strategies has not been consistent 
across clinical trials [84]. Although trials of $A \beta$ monoclonal antibodies such as solanezumab and bapineuzumab have proved effective for reducing $A \beta$ level, little improvement in cognition has been achieved for $A D$ patients. In two Phase III clinical trials in 2012, solanezumab, which was once considered the most promising drug for $A D$ treatment, failed to show significant cognition benefits. In a subsequent Phase III trial that ended in November 2016, solanezumab did not show a significant effect on slowing cognitive decline in patients mildly affected with $A D$ [85]. Recently, a more exciting Phase lb study showed that treatment with aducanumab (BIIB037), a human monoclonal antibody against aggregated $A \beta$, reduced $A \beta$ deposits in the brain in a dose- and time-dependent manner, as assessed with florbetapir-based PET imaging. This suggested a slowing of clinical progression based on scores from the Clinical Dementia Rating-Sum of Boxes and Mini Mental State Examination [86].

All in all, the failure of numerous clinical trials of antiamyloid agents can be attributed to many factors, such as inadequate preclinical data, poor brain penetration, or poor understanding of amyloid function, among others. In a review, Hardy et al. noted that " $A D$ trials done prior to obligatory amyloid-PET imaging turned out to have up to 25\% of subjects that were amyloid-negative" [20]. Thus, the unsuitable choice of trial candidates may also be one of the factors contributing to the failure of some clinical candidates.

Aside from anti-amyloid agents, a study published in 2016 suggested that gamma oscillations may be a prospect for treatment of $A D$ by reducing total amyloid levels via decreased amyloidogenesis and increased amyloid endocytosis by microglia, and the effects were not specific to one animal model [87]. In addition, Sorrentino et al. reported that mitochondrial abnormalities also play a role in the pathogenesis of $A D$ and that boosting mitochondrial function and proteostasis might decrease the formation of $A \beta$ aggregates [88]. Thus, mitochondrial proteostasis may also provide a new insight to amyloid-targeted therapies. Moreover, Ono reported that rosmarinic acid (RA) could inhibit $A \beta 40 / 42$ oligomerization and decrease oligomerinduced synaptic toxicity [41].

\section{CONCLUSIONS}

The discovery of amyloid plaques in the brain tissue of $A D$ patients and subsequent findings concerning APP genes naturally led to the amyloid cascade hypothesis. Unsurprisingly, $A \beta$ peptide plays an important role in the course of $A D$ development. In the more than 20 years since the proposal of the original hypothesis, a substantial number of published reports have helped bolster research on $A D$ and treatment strategies. Serious concerns have been raised about efficacy, however, yet new discoveries have been made. The amyloid cascade hypothesis, although still controversial, continues to help guide AD research. It is agreed that $A \beta$ oligomers, instead of amyloid plaques, constitute the primary cause of toxicity, and $A \beta 42$ seems to be more toxic than $A \beta 40$, as the length of the peptide determines the toxicity [45]. $A \beta$ oligomers disrupt synaptic activity, although $A \beta$ has now been shown not to be responsible for certain pathological effects of $A D$, as was previously presumed. An intermediate level of $A \beta$ enhances presynaptic excitation whereas elevated or reduced levels depress synaptic function. Moreover, $A \beta$ oligomers have opposite effects on excitatory and inhibitory synapses, and thus their impact on the neural circuitry varies depending on the structures of neuronal networks. A high level of $A \beta$ induced neuronal hyperexcitability, aberrant neuronal network activity, and dysfunction of slow oscillations can lead to impairment of learning and memory. Many attempts have been made to develop drugs that reduce the level of $A \beta$. In clinical trials, immunotherapy has been more successful by far than $\beta / \gamma$-secretase inhibitors. However, further studies are needed to improve cognitive outcomes in addition to removing $A \beta$ plaques more efficiently. Nevertheless, $A D$ is multifactorial disease, and a more integrated approach must be applied to increase treatment efficacy. Although immunotherapy holds promise, innovative approaches such as gamma oscillations and mitochondrial proteostasis, among others, have shown promising results. Further research may yield a more efficacious therapy. Notably, the discovery of the connection between amyloid plaques and tau aggregation indicates that future treatment of $A D$ might not be based solely on the amyloid cascade hypothesis.

\section{ACKNOWLEDGMENTS}

This study was financially supported by the National Natural Sciences Foundation of China (numbers 81330026, 81771330, 31271259), the National Key Basic Research Development Program of the Ministry of Science and Technology of China (973 Program, 2013CB945600), and a project funded by the Priority Academic Program Development of Jiangsu Higher Education Institutions.

\section{CONFLICT OF INTEREST}

The authors declare no competing financial interests.

\section{COPYRIGHT}

(C) 2018 Zhou et al. This is an open-access article released under the terms of the Creative Commons Attribution (CC BY) license, which allows the unrestricted use, distribution, and reproduction in any medium, provided the original author and source are acknowledged.

Please cite this article as: Yixiu Zhou, Yuhui Sun, Quan-Hong Ma and Yaobo Liu (2018). Alzheimer's disease: amyloid-based pathogenesis and potential therapies. Cell Stress 2(7): 150-161. doi: 10.15698/cst2018.07.143 


\section{REFERENCES}

1. Alzheimer's Disease International (2016). World Alzheimer Report 2016 summary sheet. Available at: https://www.alz.co.uk/research/worldalzheimerreport2016sheet.pdf [Accessed 03.02.2017]

2. Wittenberg R, and Hu B (2016). The Impact of Alzheimer's Disease in China. EBioMedicine 4: 22-23. doi: 10.1016/j.ebiom.2016.02.018

3. Keogh-Brown MR, Jensen HT, Arrighi HM, and Smith RD (2016). The Impact of Alzheimer's Disease on the Chinese Economy. EBioMedicine 4: 184-190. doi: 10.1016/j.ebiom.2015.12.019

4. Ricciarelli R, and Fedele E (2017). The Amyloid Cascade Hypothesis in Alzheimer's Disease: It's Time to Change Our Mind. Curr Neuropharmacol 15(6): 926-935. doi: 10.2174/1570159X15666170116143743

5. Holtzman DM, Morris JC, and Goate AM (2011). Alzheimer's disease: the challenge of the second century. Sci Transl Med 3(77): 77sr1. doi: 10.1126/scitrans/med.3002369

6. Glenner GG, and Wong CW (1984). Alzheimer's disease: initial report of the purification and characterization of a novel cerebrovascular amyloid protein. Biochem Biophys Res Commun 120(3): 885-890. doi: 10.1016/s0006-291x(84)80190-4

7. Masters CL, Simms G, Weinman NA, Multhaup G, McDonald BL, and Beyreuther K (1985). Amyloid plaque core protein in Alzheimer disease and Down syndrome. Proc Natl Acad Sci U S A 82(12): 42454249. doi: 10.1073/pnas.82.12.4245

8. Hardy J, and Selkoe DJ (2002). The amyloid hypothesis of Alzheimer's disease: progress and problems on the road to therapeutics. Science 297(5580): 353-356. doi: 10.1126/science.1072994

9. Hardy JA, and Higgins GA (1992). Alzheimer's disease: the amyloid cascade hypothesis. Science 256(5054): 184-185. doi: 10.1126/science. 1566067

10. Lee H-G, Casadesus G, Zhu X, Takeda A, Perry G, and Smith MA (2004). Challenging the amyloid cascade hypothesis: senile plaques and amyloid-beta as protective adaptations to Alzheimer disease. Ann N Y Acad Sci 1019: 1-4. doi: 10.1196/annals.1297.001

11. Bishop GM, and Robinson SR (2004). The amyloid paradox: amyloid-beta-metal complexes can be neurotoxic and neuroprotective. Brain Pathol Zurich Switz 14(4): 448-452. doi: 10.1111/j.17503639.2004.tb00089.x

12. Shankar GM, Li S, Mehta TH, Garcia-Munoz A, Shepardson NE, Smith I, Brett FM, Farrell MA, Rowan MJ, Lemere CA, Regan CM, Walsh DM, Sabatini BL, and Selkoe DJ (2008). Amyloid-beta protein dimers isolated directly from Alzheimer's brains impair synaptic plasticity and memory. Nat Med 14(8): 837-842. doi: 10.1038/nm1782

13. Jonsson T, Atwal JK, Steinberg S, Snaedal J, Jonsson PV, Bjornsson $S$, Stefansson H, Sulem P, Gudbjartsson D, Maloney J, Hoyte K, Gustafson A, Liu $\mathrm{Y}$, Lu $\mathrm{Y}$, Bhangale $\mathrm{T}$, Graham RR, Huttenlocher J, Bjornsdottir G, Andreassen OA, Jönsson EG, Palotie A, Behrens TW, Magnusson OT, Kong A, Thorsteinsdottir U, Watts RJ, and Stefansson $\mathrm{K}$ (2012). A mutation in APP protects against Alzheimer's disease and age-related cognitive decline. Nature 488(7409): 96-99. doi: $10.1038 /$ nature11283

14. He Z, Guo JL, McBride JD, Narasimhan S, Kim H, Changolkar L, Zhang B, Gathagan RJ, Yue C, Dengler C, Stieber A, Nitla M, Coulter DA, Abel T, Brunden KR, Trojanowski JQ, and Lee VM-Y (2018). Amyloid- $\beta$ plaques enhance Alzheimer's brain tau-seeded pathologies by facilitating neuritic plaque tau aggregation. Nat Med 24(1): 29-38. doi: $10.1038 / \mathrm{nm} .4443$

15. Williamson J, Goldman J, and Marder KS (2009). Genetic aspects of Alzheimer disease. The Neurologist 15(2): 80-86. doi: 10.1097/NRL.0b013e318187e76b
16. Nhan HS, Chiang K, and Koo EH (2015). The multifaceted nature of amyloid precursor protein and its proteolytic fragments: friends and foes. Acta Neuropathol 129(1): 1-19. doi: 10.1007/s00401-014-13472

17. Xia D, Watanabe H, Wu B, Lee SH, Li Y, Tsvetkov E, Bolshakov VY, Shen J, and Kelleher RJ (2015). Presenilin-1 knockin mice reveal lossof-function mechanism for familial Alzheimer's disease. Neuron 85(5): 967-981. doi: 10.1016/j.neuron.2015.02.010

18. Ben-Gedalya T, Moll L, Bejerano-Sagie M, Frere S, Cabral WA, Friedmann-Morvinski D, Slutsky I, Burstyn-Cohen T, Marini JC, and Cohen E (2015). Alzheimer's disease-causing proline substitutions lead to presenilin 1 aggregation and malfunction. EMBO J 34(22): 28202839. doi: 10.15252/embj.201592042

19. Szaruga M, Veugelen $S$, Benurwar $M$, Lismont $S$, Sepulveda-Falla $D$, Lleo A, Ryan NS, Lashley T, Fox NC, Murayama S, Gijsen H, De Strooper $B$, and Chávez-Gutiérrez $L$ (2015). Qualitative changes in human $\gamma$ secretase underlie familial Alzheimer's disease. J Exp Med 212(12): 2003-2013. doi: 10.1084/jem.20150892

20. Selkoe DJ, and Hardy J (2016). The amyloid hypothesis of Alzheimer's disease at 25 years. EMBO Mol Med 8(6): 595-608. doi: 10.15252/emmm.201606210

21. Herrup $K$ (2015). The case for rejecting the amyloid cascade hypothesis. Nat Neurosci 18(6): 794-799. doi: 10.1038/nn.4017

22. Villemagne VL, Pike KE, Chételat G, Ellis KA, Mulligan RS, Bourgeat P, Ackermann U, Jones G, Szoeke C, Salvado O, Martins R, O'Keefe G, Mathis CA, Klunk WE, Ames D, Masters CL, and Rowe CC (2011). Longitudinal assessment of $A \beta$ and cognition in aging and Alzheimer disease. Ann Neurol 69(1): 181-192. doi: 10.1002/ana.22248

23. Cramer PE, Cirrito JR, Wesson DW, Lee CYD, Karlo JC, Zinn AE, Casali BT, Restivo JL, Goebel WD, James MJ, Brunden KR, Wilson DA, and Landreth GE (2012). ApoE-directed therapeutics rapidly clear $\beta$ amyloid and reverse deficits in AD mouse models. Science 335(6075): 1503-1506. doi: 10.1126/science.1217697

24. Holmes C, Boche D, Wilkinson D, Yadegarfar G, Hopkins V, Bayer A, Jones RW, Bullock R, Love S, Neal JW, Zotova E, and Nicoll JAR (2008). Long-term effects of Abeta42 immunisation in Alzheimer's disease: follow-up of a randomised, placebo-controlled phase I trial. Lancet Lond Engl 372(9634): 216-223. doi: 10.1016/S0140-6736(08)61075-2

25. Roher AE, Maarouf CL, and Kokjohn TA (2016). Familial Presenilin Mutations and Sporadic Alzheimer's Disease Pathology: Is the Assumption of Biochemical Equivalence Justified? J Alzheimers Dis JAD 50(3): 645-658. doi: 10.3233/JAD-150757

26. Thomas JB et al. (2014). Functional connectivity in autosomal dominant and late-onset Alzheimer disease. JAMA Neurol 71(9): 1111-1122. doi: 10.1001/jamaneurol.2014.1654

27. Zheng $\mathrm{H}$, and Koo EH (2011). Biology and pathophysiology of the amyloid precursor protein. Mol Neurodegener 6(1): 27. doi: 10.1186/1750-1326-6-27

28. Mattson MP (2004). Pathways towards and away from Alzheimer's disease. Nature 430(7000): 631-639. doi: 10.1038/nature02621

29. Berridge MJ (2010). Calcium hypothesis of Alzheimer's disease. Pflugers Arch 459(3): 441-449. doi: 10.1007/s00424-009-0736-1

30. Bu G (2009). Apolipoprotein E and its receptors in Alzheimer's disease: pathways, pathogenesis and therapy. Nat Rev Neurosci 10(5): 333-344. doi: 10.1038/nrn2620

31. Rogaeva E et al. (2007). The neuronal sortilin-related receptor SORL1 is genetically associated with Alzheimer disease. Nat Genet 39(2): 168-177. doi: 10.1038/ng1943 
32. Zhang $X$, and Song $W$ (2013). The role of APP and BACE1 trafficking in APP processing and amyloid- $\beta$ generation. Alzheimers Res The 5(5): 46. doi: 10.1186/alzrt211

33. Walsh DM, and Selkoe DJ (2007). A beta oligomers - a decade of discovery. J Neurochem 101(5): 1172-1184. doi: 10.1111/j.14714159.2006.04426.x

34. De Jonghe C, Esselens C, Kumar-Singh S, Craessaerts K, Serneels S, Checler F, Annaert W, Van Broeckhoven C, and De Strooper B (2001). Pathogenic APP mutations near the gamma-secretase cleavage site differentially affect Abeta secretion and APP C-terminal fragment stability. Hum Mol Genet 10(16): 1665-1671. doi: 10.1093/hmg/10.16.1665

35. Dimitrov $M$, Alattia J-R, Lemmin $T$, Lehal R, Fligier A, Houacine J, Hussain I, Radtke F, Dal Peraro M, Beher D, and Fraering PC (2013). Alzheimer's disease mutations in APP but not $\gamma$-secretase modulators affect epsilon-cleavage-dependent AICD production. Nat Commun 4: 2246. doi: $10.1038 /$ ncomms 3246

36. Johnson RD, Schauerte JA, Chang C-C, Wisser KC, Althaus JC, Carruthers CJL, Sutton MA, Steel DG, and Gafni A (2013). Single-molecule imaging reveals aß42:aß40 ratio-dependent oligomer growth on neuronal processes. Biophys J 104(4): 894-903. doi: 10.1016/j.bpj.2012.12.051

37. Siegel G, Gerber H, Koch P, Bruestle O, Fraering PC, and Rajendran $L$ (2017). The Alzheimer's Disease $\gamma$-Secretase Generates Higher 42:40 Ratios for $\beta$-Amyloid Than for p3 Peptides. Cell Rep 19(10): 19671976. doi: 10.1016/j.celrep.2017.05.034

38. Wiltfang J, Esselmann $H$, Bibl $M$, Hüll $M$, Hampel $H$, Kessler $H$, Frölich L, Schröder J, Peters O, Jessen F, Luckhaus C, Perneczky R, Jahn $H$, Fiszer M, Maler JM, Zimmermann R, Bruckmoser R, Kornhuber J, and Lewczuk $P$ (2007). Amyloid beta peptide ratio $42 / 40$ but not $A$ beta 42 correlates with phospho-Tau in patients with low- and highCSF A beta 40 load. J Neurochem 101(4): 1053-1059. doi: 10.1111/j.1471-4159.2006.04404.x

39. Spies PE, Slats D, Sjögren JMC, Kremer BPH, Verhey FRJ, Rikkert MGMO, and Verbeek MM (2010). The cerebrospinal fluid amyloid beta42/40 ratio in the differentiation of Alzheimer's disease from nonAlzheimer's dementia. Curr Alzheimer Res 7(5): 470-476. PMID: 20043812

40. Fandos N, Pérez-Grijalba V, Pesini $P$, Olmos S, Bossa M, Villemagne VL, Doecke J, Fowler C, Masters CL, Sarasa M, and AIBL Research Group (2017). Plasma amyloid $\beta 42 / 40$ ratios as biomarkers for amyloid $\beta$ cerebral deposition in cognitively normal individuals. Alzheimers Dement Amst Neth 8: 179-187. doi: 10.1016/j.dadm.2017.07.004

41. Ono K (2017). Alzheimer's disease as oligomeropathy. Neurochem Int doi: 10.1016/j.neuint.2017.08.010

42. Saito T, Suemoto T, Brouwers N, Sleegers K, Funamoto S, Mihira N, Matsuba Y, Yamada K, Nilsson P, Takano J, Nishimura M, Iwata N, Van Broeckhoven $C$, Ihara $Y$, and Saido TC (2011). Potent amyloidogenicity and pathogenicity of $A \beta 43$. Nat Neurosci 14(8): 1023-1032. doi: $10.1038 / \mathrm{nn} .2858$

43. Willem M, Tahirovic S, Busche MA, Ovsepian SV, Chafai M, Kootar S, Hornburg D, Evans LD, Moore S, Daria A, Hampel H, Müller V, Giudici C, Nuscher B, Wenninger-Weinzierl A, Kremmer E, Heneka MT, Thal DR, Giedraitis V, Lannfelt L, Müller U, Livesey FJ, Meissner F, Herms J, Konnerth A, Marie H, and Haass C (2015). $\eta$-Secretase processing of APP inhibits neuronal activity in the hippocampus. Nature 526(7573): 443-447. doi: 10.1038/nature14864

44. Brkic M, Balusu S, Van EW, Gorlé N, Benilova I, Kremer A, Van IH, Moons L, De BS, Kanazir S, Libert C, and Vandenbroucke RE (2015). Amyloid $\beta$ Oligomers Disrupt Blood-CSF Barrier Integrity by Activating
Matrix Metalloproteinases. J Neurosci Off J Soc Neurosci 35(37): 12766-12778. doi: 10.1523/JNEUROSCI.0006-15.2015

45. Canter RG, Penney J, and Tsai L-H (2016). The road to restoring neural circuits for the treatment of Alzheimer's disease. Nature 539(7628): 187-196. doi: 10.1038/nature20412

46. Kamenetz F, Tomita T, Hsieh H, Seabrook G, Borchelt D, Iwatsubo T, Sisodia S, and Malinow R (2003). APP processing and synaptic function. Neuron 37(6): 925-937. doi: 10.1016/s0896-6273(03)00124-7

47. Wei W, Nguyen LN, Kessels HW, Hagiwara H, Sisodia S, and Malinow $R$ (2010). Amyloid beta from axons and dendrites reduces local spine number and plasticity. Nat Neurosci 13(2): 190-196. doi: $10.1038 / \mathrm{nn} .2476$

48. Shankar GM, Bloodgood BL, Townsend M, Walsh DM, Selkoe DJ, and Sabatini BL (2007). Natural oligomers of the Alzheimer amyloidbeta protein induce reversible synapse loss by modulating an NMDAtype glutamate receptor-dependent signaling pathway. J Neurosci Off J Soc Neurosci 27(11): 2866-2875. doi: 10.1523/JNEUROSCI.497006.2007

49. Sheng M, Sabatini BL, and Südhof TC (2012). Synapses and Alzheimer's disease. Cold Spring Harb Perspect Biol 4(5). doi: 10.1101/cshperspect.a005777

50. Collingridge GL, Peineau S, Howland JG, and Wang YT (2010). Longterm depression in the CNS. Nat Rev Neurosci 11(7): 459-473. doi: $10.1038 / \mathrm{nrn} 2867$

51. Palop JJ, and Mucke L (2010). Amyloid-beta-induced neuronal dysfunction in Alzheimer's disease: from synapses toward neural networks. Nat Neurosci 13(7): 812-818. doi: 10.1038/nn.2583

52. Kayed R, and Lasagna-Reeves CA (2013). Molecular mechanisms of amyloid oligomers toxicity. J Alzheimers Dis JAD 33 Suppl 1: S67-78. doi: 10.3233/JAD-2012-129001

53. Laurén J, Gimbel DA, Nygaard HB, Gilbert JW, and Strittmatter SM (2009). Cellular prion protein mediates impairment of synaptic plasticity by amyloid-beta oligomers. Nature 457(7233): 1128-1132. doi: 10.1038/nature07761

54. Kim T, Vidal GS, Djurisic M, William CM, Birnbaum ME, Garcia KC, Hyman BT, and Shatz CJ (2013). Human LilrB2 is a $\beta$-amyloid receptor and its murine homolog PirB regulates synaptic plasticity in an Alzheimer's model. Science 341(6152): 1399-1404. doi: 10.1126/science. 1242077

55. Yamamoto N, Matsubara E, Maeda S, Minagawa H, Takashima A, Maruyama W, Michikawa M, and Yanagisawa K (2007). A gangliosideinduced toxic soluble Abeta assembly. Its enhanced formation from Abeta bearing the Arctic mutation. J Biol Chem 282(4): 2646-2655. doi: 10.1074/jbc.M606202200

56. Zhao W-Q, De Felice FG, Fernandez S, Chen H, Lambert MP, Quon MJ, Krafft GA, and Klein WL (2008). Amyloid beta oligomers induce impairment of neuronal insulin receptors. FASEB J Off Publ Fed Am Soc Exp Biol 22(1): 246-260. doi: 10.1096/fj.06-7703com

57. Townsend M, Mehta T, and Selkoe DJ (2007). Soluble Abeta inhibits specific signal transduction cascades common to the insulin receptor pathway. J Biol Chem 282(46): 33305-33312. doi: 10.1074/jbc.M610390200

58. Magdesian MH, Carvalho MMVF, Mendes FA, Saraiva LM, Juliano MA, Juliano L, Garcia-Abreu J, and Ferreira ST (2008). Amyloid-beta binds to the extracellular cysteine-rich domain of Frizzled and inhibits Wnt/beta-catenin signaling. J Biol Chem 283(14): 9359-9368. doi: 10.1074/jbc.M707108200

59. Di Scala C, Troadec J-D, Lelièvre C, Garmy N, Fantini J, and Chahinian $H$ (2014). Mechanism of cholesterol-assisted oligomeric channel 
formation by a short Alzheimer $\beta$-amyloid peptide. J Neurochem 128(1): 186-195. doi: 10.1111/jnc.12390

60. Kayed R, Sokolov Y, Edmonds B, Mclntire TM, Milton SC, Hall JE, and Glabe CG (2004). Permeabilization of lipid bilayers is a common conformation-dependent activity of soluble amyloid oligomers in protein misfolding diseases. J Biol Chem 279(45): 46363-46366. doi: 10.1074/jbc.C400260200

61. Abramov E, Dolev I, Fogel H, Ciccotosto GD, Ruff E, and Slutsky I (2009). Amyloid-beta as a positive endogenous regulator of release probability at hippocampal synapses. Nat Neurosci 12(12): 1567-1576. doi: $10.1038 / \mathrm{nn} .2433$

62. Palop JJ, Chin J, Roberson ED, Wang J, Thwin MT, Bien-Ly N, Yoo J, Ho KO, Yu G-Q, Kreitzer A, Finkbeiner S, Noebels JL, and Mucke L (2007). Aberrant excitatory neuronal activity and compensatory remodeling of inhibitory hippocampal circuits in mouse models of Alzheimer's disease. Neuron 55(5): 697-711. doi: 10.1016/j.neuron.2007.07.025

63. Busche MA, and Konnerth A (2016). Impairments of neural circuit function in Alzheimer's disease. Philos Trans R Soc Lond B Biol Sci 371(1700). doi: 10.1098/rstb.2015.0429

64. Šišková Z, Justus D, Kaneko H, Friedrichs D, Henneberg N, Beutel T, Pitsch J, Schoch S, Becker A, von der Kammer H, and Remy S (2014). Dendritic structural degeneration is functionally linked to cellular hyperexcitability in a mouse model of Alzheimer's disease. Neuron 84(5): 1023-1033. doi: 10.1016/j.neuron.2014.10.024

65. Walsh DM, Klyubin I, Fadeeva JV, Cullen WK, Anwyl R, Wolfe MS, Rowan MJ, and Selkoe DJ (2002). Naturally secreted oligomers of amyloid beta protein potently inhibit hippocampal long-term potentiation in vivo. Nature 416(6880): 535-539. doi: 10.1038/416535a

66. Kullmann DM, and Lamsa KP (2007). Long-term synaptic plasticity in hippocampal interneurons. Nat Rev Neurosci 8(9): 687-699. doi: $10.1038 / \mathrm{nrn} 2207$

67. Snyder EM, Nong Y, Almeida CG, Paul S, Moran T, Choi EY, Nairn AC, Salter MW, Lombroso PJ, Gouras GK, and Greengard P (2005). Regulation of NMDA receptor trafficking by amyloid-beta. Nat Neurosci 8(8): 1051-1058. doi: 10.1038/nn1503

68. Li S, Jin M, Koeglsperger T, Shepardson NE, Shankar GM, and Selkoe DJ (2011). Soluble A $\beta$ oligomers inhibit long-term potentiation through a mechanism involving excessive activation of extrasynaptic NR2B-containing NMDA receptors. J Neurosci Off J Soc Neurosci 31(18): 6627-6638. doi: 10.1523/JNEUROSCI.0203-11.2011

69. Um JW, Nygaard HB, Heiss JK, Kostylev MA, Stagi M, Vortmeyer A, Wisniewski T, Gunther EC, and Strittmatter SM (2012). Alzheimer amyloid- $\beta$ oligomer bound to postsynaptic prion protein activates Fyn to impair neurons. Nat Neurosci 15(9): 1227-1235. doi: 10.1038/nn.3178

70. Vossel KA, Beagle AJ, Rabinovici GD, Shu H, Lee SE, Naasan G, Hegde $M$, Cornes SB, Henry ML, Nelson AB, Seeley WW, Geschwind MD, Gorno-Tempini ML, Shih T, Kirsch HE, Garcia PA, Miller BL, and Mucke $L$ (2013). Seizures and epileptiform activity in the early stages of Alzheimer disease. JAMA Neurol 70(9): 1158-1166. doi: 10.1001/jamaneurol.2013.136

71. Vassar R (2014). BACE1 inhibitor drugs in clinical trials for Alzheimer's disease. Alzheimers Res Ther 6(9): 89. doi: 10.1186/s13195014-0089-7

72. Jack CR, Lowe VJ, Weigand SD, Wiste HJ, Senjem ML, Knopman DS, Shiung MM, Gunter JL, Boeve BF, Kemp BJ, Weiner M, Petersen RC and Alzheimer's Disease Neuroimaging Initiative (2009). Serial PIB and MRI in normal, mild cognitive impairment and Alzheimer's disease: implications for sequence of pathological events in Alzheimer's dis- ease. Brain J Neurol 132(Pt 5): 1355-1365. doi: 10.1093/brain/awp062

73. De Strooper B (2014). Lessons from a failed $\gamma$-secretase Alzheimer trial. Cell 159(4): 721-726. doi: 10.1016/j.cell.2014.10.016

74. Bachurin SO, Bovina EV, and Ustyugov AA (2017). Drugs in Clinical Trials for Alzheimer's Disease: The Major Trends. Med Res Rev 37(5): 1186-1225. doi: 10.1002/med.21434

75. Mullard A (2017). BACE inhibitor bust in Alzheimer trial. Nat Rev Drug Discov 16(3): 155. doi: 10.1038/nrd.2017.43

76. Cebers G, Alexander RC, Haeberlein SB, Han D, Goldwater R, Ereshefsky L, Olsson T, Ye N, Rosen L, Russell M, Maltby J, Eketjäll S, and Kugler AR (2017). AZD3293: Pharmacokinetic and Pharmacodynamic Effects in Healthy Subjects and Patients with Alzheimer's Disease. J Alzheimers Dis JAD 55(3): 1039-1053. doi: 10.3233/jad160701

77. Goyal D, Shuaib S, Mann S, and Goyal B (2017). Rationally Designed Peptides and Peptidomimetics as Inhibitors of Amyloid- $\beta$ (A $\beta$ ) Aggregation: Potential Therapeutics of Alzheimer's Disease. ACS Comb Sci 19(2): 55-80. doi: 10.1021/acscombsci.6b00116

78. Schenk D (2002). Amyloid-beta immunotherapy for Alzheimer's disease: the end of the beginning. Nat Rev Neurosci 3(10): 824-828. doi: $10.1038 /$ nrn938

79. Orgogozo J-M, Gilman S, Dartigues J-F, Laurent B, Puel M, Kirby LC, Jouanny P, Dubois B, Eisner L, Flitman S, Michel BF, Boada M, Frank A, and Hock $C$ (2003). Subacute meningoencephalitis in a subset of patients with $A D$ after Abeta42 immunization. Neurology 61(1): 46-54. doi: 10.1212/01.wnl.0000073623.84147.a8

80. Paquet $C$, Amin J, Mouton-Liger F, Nasser M, Love S, Gray F, Pickering RM, Nicoll JAR, Holmes C, Hugon J, and Boche D (2015). Effect of active $A \beta$ immunotherapy on neurons in human Alzheimer's disease. J Pathol 235(5): 721-730. doi: 10.1002/path.4491

81. Mulder CK, Dong $Y$, Brugghe HF, Timmermans HA, Tilstra W, Westdijk J, Van ER, Van HS, Hoogerhout P, and Eisel UL (2016). Immunization with Small Amyloid- $\beta$-derived Cyclopeptide Conjugates Diminishes Amyloid- $\beta$-Induced Neurodegeneration in Mice. J Alzheimers Dis JAD 52(3): 1111, 1111-1123. doi: 10.3233/JAD-151136

82. Vandenberghe R, Riviere ME, Caputo A, Sovago J, Maguire RP, Farlow M, Marotta G, Sanchez-Valle R, Scheltens P, Ryan JM, and Graf $A$ (2017). Active $A \beta$ immunotherapy CAD106 in Alzheimer's disease: $A$ phase $2 b$ study. Alzheimers Dement N Y N 3(1): 10-22. doi: 10.1016/j.trci.2016.12.003

83. Fu L, Li Y, Hu Y, Zheng Y, Yu B, Zhang H, Wu J, Wu H, Yu X, and Kong $W(2017)$. Norovirus $P$ particle-based active $A \beta$ immunotherapy elicits sufficient immunogenicity and improves cognitive capacity in a mouse model of Alzheimer's disease. Sci Rep 7: 41041-41041. doi: $10.1038 /$ srep41041

84. Pohanka M (2016). Vaccination to Alzheimer Disease. Is it a Promising Tool or a Blind Way? Curr Med Chem 23(14): 1432-1441. doi: 10.2174/0929867323666160418114733

85. Sacks CA, Avorn J, and Kesselheim AS (2017). The Failure of Solanezumab - How the FDA Saved Taxpayers Billions. N Engl J Med 376(18): 1706-1708. doi: 10.1056/NEJMp1701047

86. Sevigny J, Chiao $P$, Bussière $T$, Weinreb $P H$, Williams L, Maier $M$, Dunstan R, Salloway S, Chen T, Ling Y, O'Gorman J, Qian F, Arastu M, Li M, Chollate S, Brennan MS, Quintero-Monzon O, Scannevin RH, Arnold HM, Engber T, Rhodes K, Ferrero J, Hang Y, Mikulskis A, Grimm J, Hock C, Nitsch RM, and Sandrock A (2016). The antibody aducanumab reduces $A \beta$ plaques in Alzheimer's disease. Nature 537(7618): 50-56. doi: 10.1038/nature19323 
87. laccarino HF, Singer AC, Martorell AJ, Rudenko A, Gao F, Gillingham TZ, Mathys H, Seo J, Kritskiy O, Abdurrob F, Adaikkan C, Canter RG, Rueda R, Brown EN, Boyden ES, and Tsai L-H (2016). Gamma frequency entrainment attenuates amyloid load and modifies microglia. Nature 540(7632): 230-235. doi: 10.1038/nature20587
88. Sorrentino V, Romani M, Mouchiroud L, Beck JS, Zhang H, D'Amico D, Moullan N, Potenza F, Schmid AW, Rietsch S, Counts SE, and Auwerx J (2017). Enhancing mitochondrial proteostasis reduces amyloid$\beta$ proteotoxicity. Nature 552(7684): 187-193. doi: $10.1038 /$ nature25143 